\title{
Phylogeny and differentiation of species of the genus Gluconacetobacter and related taxa based on multilocus sequence analyses of housekeeping genes and reclassification of Acetobacter xylinus subsp. sucrofermentans as Gluconacetobacter sucrofermentans (Toyosaki et al. 1996) sp. nov., comb. nov.
}

Correspondence Ilse Cleenwerck ilse.cleenwerck@ugent.be
Ilse Cleenwerck, ${ }^{1}$ Paul De Vos ${ }^{1,2}$ and Luc De Vuyst ${ }^{3}$

\author{
${ }^{1}$ BCCM/LMG Bacteria Collection, Faculty of Sciences, Ghent University, K. L. Ledeganckstraat 35, \\ B-9000 Ghent, Belgium \\ ${ }^{2}$ Laboratory of Microbiology, Faculty of Sciences, Ghent University, K. L. Ledeganckstraat 35, \\ B-9000 Ghent, Belgium \\ ${ }^{3}$ Research Group of Industrial Microbiology and Food Biotechnology, Faculty of Sciences and \\ Bioengineering Sciences, Vrije Universiteit Brussel, Pleinlaan 2, B-1050 Brussels, Belgium
}

\begin{abstract}
Three housekeeping genes ( $d n a K$, groEL and $r p o B$ ) of strains belonging to the genus Gluconacetobacter (37 strains) or related taxa (38 strains) were sequenced. Reference strains of the 15 species of the genus Gluconacetobacter were included. Phylogenetic trees generated using these gene sequences confirmed the existence of two phylogenetic groups within the genus Gluconacetobacter. These groups clustered separately in trees constructed using concatenated sequences of the three genes, indicating that the genus Gluconacetobacter should not remain a single genus and should be split, as suggested previously. Multilocus sequence analysis (MLSA) of the three housekeeping genes also proved useful for species differentiation in the family Acetobacteraceae. It also suggested that Gluconacetobacter xylinus LMG 18788, better known as the type and only strain of Acetobacter xylinus subsp. sucrofermentans, represents a distinct species in the genus Gluconacetobacter, and is not a true G. xylinus strain. In previous studies, this strain showed less than $70 \%$ DNA relatedness to the type strains of $G$. xylinus and Gluconacetobacter nataicola, the phylogenetically nearest relatives, and could be distinguished from them phenotypically. Additionally, AFLP and (GTG) 5 -PCR DNA fingerprinting data supported its reclassification within a distinct species. The name Gluconacetobacter sucrofermentans (Toyosaki et al. 1996) sp. nov., comb. nov. is proposed.
\end{abstract}

The genus Gluconacetobacter belongs to the family Acetobacteraceae (Gillis \& De Ley, 1980) of the Alphaproteobacteria and was proposed by Yamada et al. (1997, 1998) for strains assigned to the genus Acetobacter at that time that contained ubiquinone Q-10 as the major respiratory

Abbreviations: $A A B$, acetic acid bacteria; AFLP, amplified fragment length polymorphism; MLSA, multilocus sequence analysis.

The GenBank/EMBL/DDBJ accession numbers for the dnaK, groEL and $r p o B$ sequences reported in this paper are FN391590-FN391808 and FN421342-FN421344, as detailed in Fig. 1.

Strain details, a summary of sequence similarity for various genes and additional phylogenetic trees are available as supplementary material with the online version of this paper. quinone. As a result, Acetobacter xylinus, A. liquefaciens, A. hansenii, A. diazotrophicus and A. europaeus were reclassified in the genus Gluconacetobacter as new combinations (Yamada et al. 1997, 1998). However, the two subspecies of A. xylinus, namely A. xylinus subsp. xylinus and A. xylinus subsp. sucrofermentans (Toyosaki et al., 1995, 1996), were not mentioned in the reclassification. At the time of writing, 15 species with validly published names exist in the genus Gluconacetobacter, which is divided phylogenetically into two groups based on 16S rRNA gene sequence analysis, namely the Gluconacetobacter xylinus species group and the Gluconacetobacter liquefaciens species group (Dellaglio et al., 2005; Yamada \& Yukphan, 2008). These two groups both consist of closely related species, sharing 
more than $98.1 \%$ 16S rRNA gene sequence similarity, but the two groups themselves are not so tightly linked. For this reason, the question has been raised whether Gluconacetobacter should remain a single genus (Yamada \& Yukphan, 2008). At present, confusion also exists regarding the taxonomic status of G. xylinus LMG 18788 (=JCM $9730=$ DSM 15973), better known as the type and only known strain of A. xylinus subsp. sucrofermentans. Based on its $16 \mathrm{~S}$ rRNA gene sequence, this strain is a member of the G. xylinus species group (Dellaglio et al., 2005; Lisdiyanti et al., 2006), but its allocation at the species level is unclear. Firstly, there are discrepancies in the DNA relatedness values reported for this strain with the type strain of G. xylinus. According to Lisdiyanti et al. (2006), the two strains share a DNA relatedness of $70 \%$, whereas, according to Toyosaki et al. (1995) and Dellaglio et al. (2005), they share DNA relatedness of 56-58\%. Secondly, the (GTG) $)_{5}$-PCR DNA fingerprint of LMG 18788 is different from those of other true G. xylinus strains (De Vuyst et al., 2008). Thirdly, according to Toyosaki et al. (1995) and Kojima et al. (1998), the strain shows phenotypic characteristics that differentiate it from other $G$. xylinus strains.

In the present study, additional analyses were performed on reference strains of the species of the genus Gluconacetobacter (37 strains) and related taxa (38 strains) (Supplementary Table S1, available in IJSEM Online) in order to obtain a better view of their phylogeny and to clarify the taxonomic position of strain LMG 18788.

The strains were cultivated on GY agar ( $5 \%$ glucose, $1 \%$ yeast extract, $1.5 \%$ agar; w/v) or GYAE agar $(5 \% \mathrm{w} / \mathrm{v}$ glucose, $1 \% \mathrm{w} / \mathrm{v}$ yeast extract, $1.5 \% \mathrm{w} / \mathrm{v}$ agar, $2 \% \mathrm{v} / \mathrm{v}$ ethanol, $1 \% \mathrm{v} / \mathrm{v}$ acetic acid; the latter two components were sterilized separately by filtration and added aseptically to the autoclaved medium) and, in a few cases, on the medium suggested by the provider, by incubation at $28{ }^{\circ} \mathrm{C}$ under aerobic conditions. DNA was extracted using the method described previously (Cleenwerck et al., 2009).

A phylogenetic tree based on 16S rRNA gene sequences, retrieved from EMBL, of type strains of the species of the family Acetobacteraceae was constructed with the BioNumerics 4.61 software package (Applied Maths) using the neighbour-joining method (Saitou \& Nei, 1987). The robustness of the branches was evaluated by bootstrap resamplings of the data (Felsenstein, 1985). The topology of the tree was found to be similar to that of trees constructed previously (Cleenwerck \& De Vos, 2008; Yamada \& Yukphan, 2008) and confirmed the existence of the two, not so tightly linked species groups within the genus Gluconacetobacter (Supplementary Fig. S1). The analysis also confirmed that strain LMG 18788 is a member of the G. xylinus species group, with strains of Gluconacetobacter swingsii, G. europaeus, G. xylinus, G. nataicola, G. oboediens and G. intermedius as its closest relatives, sharing 99.3-99.8 \% 16S rRNA gene sequence similarity (Supplementary Table S2).
Several studies have shown that sequences of housekeeping genes are superior to $16 \mathrm{~S}$ rRNA gene sequences for determining phylogenetic relationships of closely related species (Naser et al., 2005; Martens et al., 2007; De Bruyne et al., 2007; Brady et al., 2008). To avoid uncovered horizontal gene transfer or recombinations in a single gene resulting in a misleading phylogenetic signal, it has been recommended to examine a minimum of three housekeeping genes (Konstantinidis et al., 2006). In this study, ten genes (recA, dnaK, rpoB, atpD, groEL, $g \ln A, t h r C, g y r A$, glt $A$ and infB) were evaluated for the construction of a multilocus sequence analysis (MLSA) framework for acetic acid bacteria (AAB). The genes $a t p D, g \ln A, g y r A$ and $\inf B$ were found in multiple copies in the complete genome sequences of $\mathrm{AAB}$ available at the start of this study (Gluconobacter oxydans $621 \mathrm{H}$ and Granulibacter bethesdensis CGDNIH1 ${ }^{\mathrm{T}}$; http://www.ncbi.nlm.nih.gov/) and were, for this reason, discarded from further analyses. For the remaining genes, primers for their amplification were designed on the basis of the two genome sequences of $\mathrm{AAB}$ (Table 1) and tested in PCRs on a subset of reference strains using the amplification conditions described by Naser et al. (2005) and an annealing temperature of $55^{\circ} \mathrm{C}$. These PCRs resulted in a single amplification product of the expected size for nearly all tested strains for $d n a K, r p o B$ and groEL, whereas, for the other three genes ( $r e c A, t h r C$ and $g l t A$ ), a relatively large number of the tested strains yielded multiple amplification products or no product at all (not shown). In the present study, it was decided to investigate the 75 strains shown in Supplementary Table S1, by MLSA of the genes dnaK (encoding a heat-shock protein), rрoB (encoding the $\beta$-subunit of bacterial RNA polymerase) and groEL (encoding a chaperonin protein).

Primers for sequencing of the three selected genes (Table 1) were, as for the amplification primers, designed on the basis of the genome sequences of Gluconobacter oxydans $621 \mathrm{H}$ and Granulibacter bethesdensis $\mathrm{CGDNIH1}^{\mathrm{T}}$. Amplification and sequencing of the 75 strains were performed using the conditions described by Naser et al. (2005) but with optimized annealing temperatures for amplification, namely $55{ }^{\circ} \mathrm{C}$ for $d n a K$ and groEL and $50{ }^{\circ} \mathrm{C}$ for $r p o B$ for most strains. For strains of G. azotocaptans, G. diazotrophicus, G. johannae and G. frateurii, an annealing temperature of 46 or $58{ }^{\circ} \mathrm{C}$ was used. The primer combinations dnaK-01-F/dnaK-02-R, groEL-10-F/groEL-11-R and rpoB01-F/rpoB-02-R amplified the target genes of most strains. Where necessary, alternative primer combinations were used, namely dnaK-01-F/dnaK-04-R for strains of $G$. azotocaptans, G. diazotrophicus and G. johannae, rpoB-01F/rpoB-07-R for strains of G. thailandicus and Kozakia baliensis LMG $21812^{\mathrm{T}}$ and rpoB-01-F/rpoB-07-R together with rpoB-03-F/rpoB-02-R for strains of G. oxydans. For Saccharibacter floricola LMG $23170^{\mathrm{T}}$, none of the genes could be sequenced with the primers listed in Table 1. Raw sequence data were transferred to the AutoAssember 1.4.0 software (Applied Biosystems) for assembly of consensus sequences by manual alignment. Phylogenetic trees based 
Table 1. Amplification and sequencing primers used in this study

Primer positions are given relative to the genome sequence of $G$. oxydans $621 \mathrm{H}$.

\begin{tabular}{|c|c|c|}
\hline Primer & Sequence $\left(5^{\prime}-3^{\prime}\right)$ & Position \\
\hline dnaK-01-F & CTGCGCATCATCAACGAGCC & 925719-925738 \\
\hline dnaK-02-R & CTCACGCTCGCCCTGATAGA & $926546-926527$ \\
\hline dnaK-03-F & TTCGACGTSTCCATCCTCGA & $925818-825837$ \\
\hline dnaK-04-R & TTGGTCGGGATCGTCGTGTT & $926470-925451$ \\
\hline groEL-10-F & ACAAGTTCGAGAACATGGGC & 2083114-2083133 \\
\hline groEL-11-R & TCCTTGCGCTCCTTCACCTC & 2084104-2084085 \\
\hline groEL-12-F & TSAAGCGCGGCATCGACAA & 2083270-2083288 \\
\hline groEL-13-F & CTGATCCACGAAAAGAAGCT & 2083584-2083603 \\
\hline groEL-14-R & TGCAACGGCCCTTGATGTC & 2083962-208 \\
\hline groEL-15-R & AGCTTCTTTTCGTGGATCAG & $3-2083584$ \\
\hline rpoB-01-F & GATAACGGCACCTTCATCAT & $405644-405625$ \\
\hline rpoB-02-R & AGATTGTCGATATCGTCGAT & $404620-404639$ \\
\hline rpoB-03-F & GATCACGACAAGGGCAAGAC & 405566 \\
\hline rpoB-04-F & CCAAGCTGACCGCSCGTA & $405157-405140$ \\
\hline rpoB-05-R & ATGTTCATCTTCACACGACCG & $404743-404763$ \\
\hline rpoB-06-R & TACGSGCGGTCAGCTTGG & $405140-405157$ \\
\hline rpoB-07-R & AGRCGCATGTTCATCTTSA & $404737-404755$ \\
\hline recA_A_F & AAGGCTCGATCATGCGCATG & $1676846-1676827$ \\
\hline recA_A_R & AYCTTGCTGATGCCTTCWCC & $1676104-1676121$ \\
\hline thrC_A_F & GAACTGTTYCACGGCCCGAC & 2048229-2048210 \\
\hline thrC_A_R & TCCAGCARTTCGAACAGCA & 2047559-2047577 \\
\hline gltA_A_F & CTTCCGCCGCGATGCSCATCC & $2188601-2188581$ \\
\hline gltA_A_R & ACAGCACSGTGAACATGCT & $2187820-2187838$ \\
\hline
\end{tabular}

on concatenated and individual $d n a K$, groEL and $r p o B$ gene sequences were constructed with the BioNumerics 4.61 software package using the neighbour-joining and maximum-parsimony (Felsenstein, 1985) methods. The robustness of the branches was evaluated by bootstrap resamplings of the data (Felsenstein, 1985).

The neighbour-joining and maximum-parsimony trees based on concatenated dnaK, groEL and rpoB gene sequences (Fig. 1 and Supplementary Fig. S2) showed very similar topologies, and were also largely in agreement with the constructed 16S rRNA gene sequence-based tree (Supplementary Fig. S1), illustrating an overall consistency of the data. The G. xylinus and G. liquefaciens species groups were visible in both concatenated housekeeping gene-based trees, but they did not cluster together, indicating that the genus Gluconacetobacter should not remain as a single genus, as suggested previously (Yamada \& Yukphan, 2008). At present, several phenotypic features have been suggested to differentiate strains of the two Gluconacetobacter species groups, such as flagella, motility and production of 2,5-diketogluconic acid, $\gamma$-pyrone and a water-soluble brown pigment. However, some of these features have previously been reported to be of little use for the differentiation of AAB (Cleenwerck \& De Vos, 2008). For this reason, other differentiating features should be looked for before splitting the genus, following the recommendations of Tindall et al. (2010) regarding descriptions of new genera.

Phylogenetic trees based on the concatenated dnaK, groEL and $r p o B$ gene sequences also delineated all species, and revealed high bootstrap values at the species level, namely $\geqslant 99 \%$ in the neighbour-joining tree and $\geqslant 96 \%$ in the maximum-parsimony tree, except for G. xylinus (Fig. 1 and Supplementary Fig. S2). These results show the usefulness of MLSA for species differentiation in the family Acetobacteraceae. Trees based on the individual dnaK, groEL or $r p o B$ gene sequences (Supplementary Figs S3-S5) also appeared useful for this purpose, as they showed similar topologies to those based on the concatenated housekeeping gene sequences. However, the bootstrap values at the species level were generally lower in the single-gene-based trees, indicating that they are less reliable for allocation of $\mathrm{AAB}$ at the species level.

For G. xylinus, low bootstrap values (58 and $52 \%$, respectively) were obtained in the neighbour-joining and maximum-parsimony trees based on the concatenated housekeeping gene sequences. These lower bootstrap values were caused by LMG 18788, and were reflected in the sequence similarities for $d n a K$, groEL and $r p o B$ obtained for this strain (Supplementary Table S2). LMG 18788 showed sequence similarities of $96.6 \%$ (dnaK), 98.098.3\% (groEL) and 95.5-95.7\% (rpoB) with G. xylinus strains LMG $1515^{\mathrm{T}}$ and LMG 1518, whereas strains within the other species of the G. xylinus species group showed at least $99.0 \%$ dnaK, $99.2 \%$ groEL and $98.8 \%$ rpoB gene sequence similarity. In addition, the sequence similarities obtained for LMG 18788 were lower than or comparable to sequence similarities obtained between strains of $G$. oboediens and G. intermedius (97.0-97.7\% for dnaK, 98.098.3\% for groEL and $95.6-95.9 \%$ for $r p o B$ ) and between strains of G. azotocaptans and G. johannae (99.0-99.2\% for dnaK, $98.1-98.6 \%$ for groEL and $95.9-96.5 \%$ for $r p o B)$. Moreover, LMG 18788 showed greater $r p o B$ gene sequence similarity to G. nataicola LMG $1536^{\mathrm{T}}(96.0 \%)$ than with G. xylinus strains LMG $1515^{\mathrm{T}}$ and LMG 1518 (95.7 and $95.5 \%$, respectively). Taken together, these results suggest clearly that LMG 18788 represents a distinct species in the G. xylinus species group.

LMG 18788 and other strains of the G. xylinus species group were subjected to (GTG) $)_{5}$-PCR and amplified fragment length polymorphism (AFLP) DNA fingerprinting, as described previously (De Vuyst et al., 2008; Cleenwerck et al., 2009), to obtain a more detailed view of their genomic relatedness. Cluster analysis of the DNA fingerprints obtained revealed a separate position for LMG 18788 (Fig. 2), again indicating that the strain represents a distinct Gluconacetobacter species.

The DNA base composition of LMG 18788 was determined following the method described by Mesbah et al. (1989) using a Waters Breeze HPLC system and XBridge Shield RP18 column. The solvent used was $0.02 \mathrm{M} \mathrm{NH}_{4} \mathrm{H}_{2} \mathrm{PO}_{4}$ $(\mathrm{pH} 4.0)$ and $1.5 \%(\mathrm{v} / \mathrm{v})$ acetonitrile. Non-methylated 


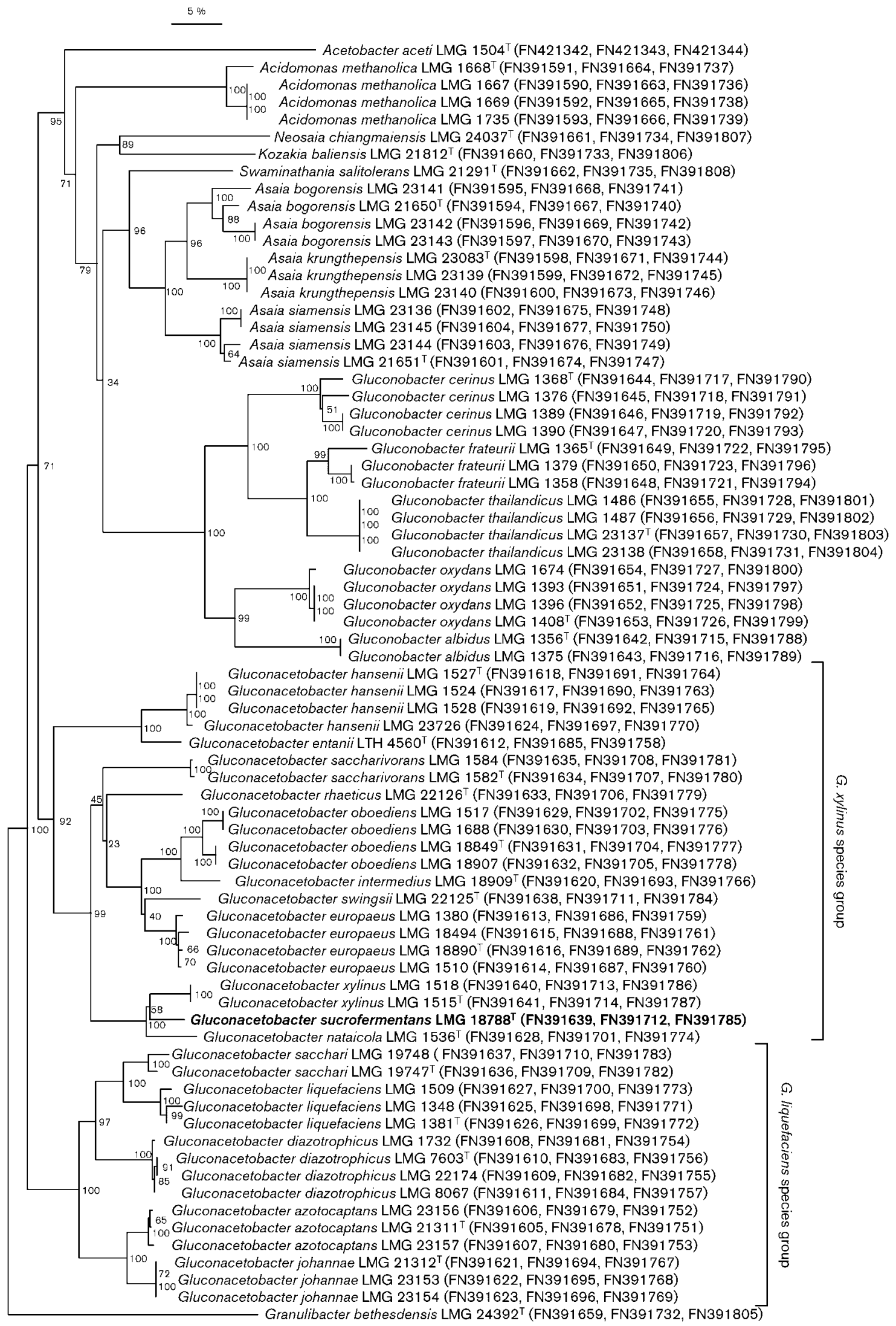


Fig. 1. Neighbour-joining tree based on concatenated $d n a K$, gro $E L$ and $r p o B$ gene sequences, showing the relationships of species of the genus Gluconacetobacter and related species. Granulibacter bethesdensis LMG $24392^{\top}$ was used as an outgroup. Numbers at branching points are percentage bootstrap values based on 500 replications. Bar, $5 \%$ sequence divergence.

lambda phage DNA (Sigma) and DNA from Escherichia coli LMG 2093 were used as calibration reference and control, respectively. The DNA G $+\mathrm{C}$ content of LMG 18788 was $62.7 \mathrm{~mol} \%$, which was very similar to the value reported previously (62.3 mol\%; Toyosaki et al., 1995). The value was also within the expected $\mathrm{G}+\mathrm{C}$ content range of the G. xylinus species group (57-64 mol\%) (Dellaglio et al., 2005; Lisdiyanti et al., 2006).

(a)

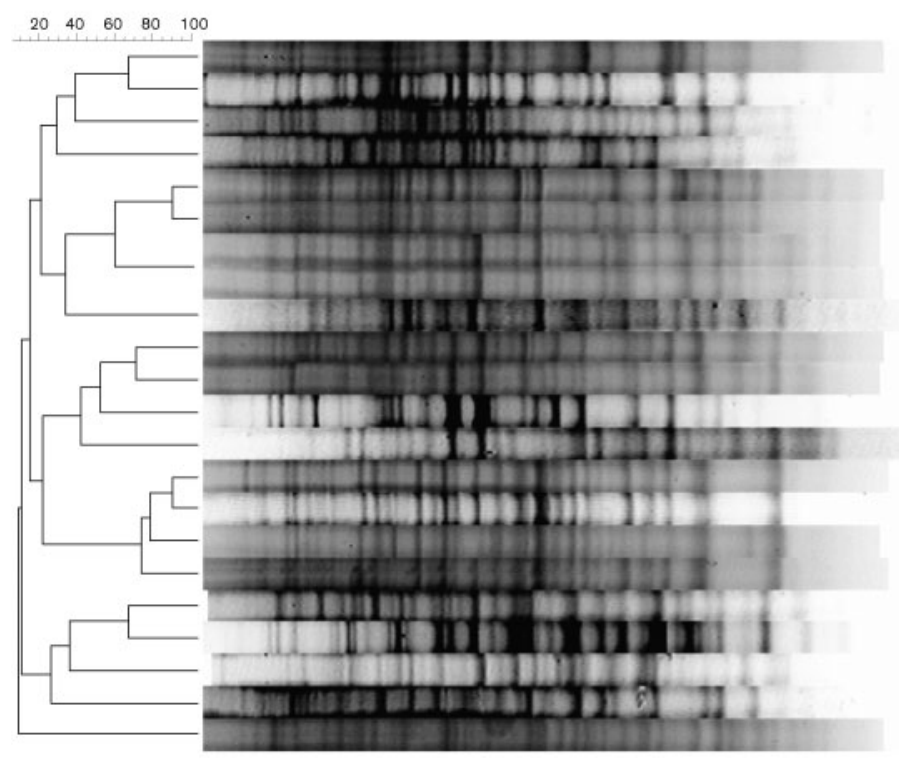

\begin{tabular}{ll} 
LMG $1582^{\top}$ & G. saccharivorans \\
LMG 1584 & \\
\hline LMG $22125^{\top}$ & G. swingsii \\
\hline LMG $22126^{\top}$ & G. rhaeticus \\
\hline LMG $18849^{\top}$ & \\
LMG 18907 & G. oboediens \\
LMG 1688 & \\
LMG 1517 & \\
\hline LMG $18909^{\top}$ & G. intermedius \\
\hline LMG 18494 & \\
LMG $18890^{\top}$ & G. europaeus \\
LMG 1510 & \\
LMG 1380 & \\
\hline LMG $1527^{\top}$ & \\
LMG 1528 & G. hansenii \\
LMG 23726 & \\
LMG 1524 & \\
\hline LMG $1515^{\top}$ & G. xylinus \\
LMG 1518 & G. entanii \\
\hline LTH $4560^{\top}$ & G. sucrofermentans \\
\hline LMG $18788^{\top}$ & G... \\
\hline LMG $1536^{\top}$ & G. nataicola
\end{tabular}

(b)

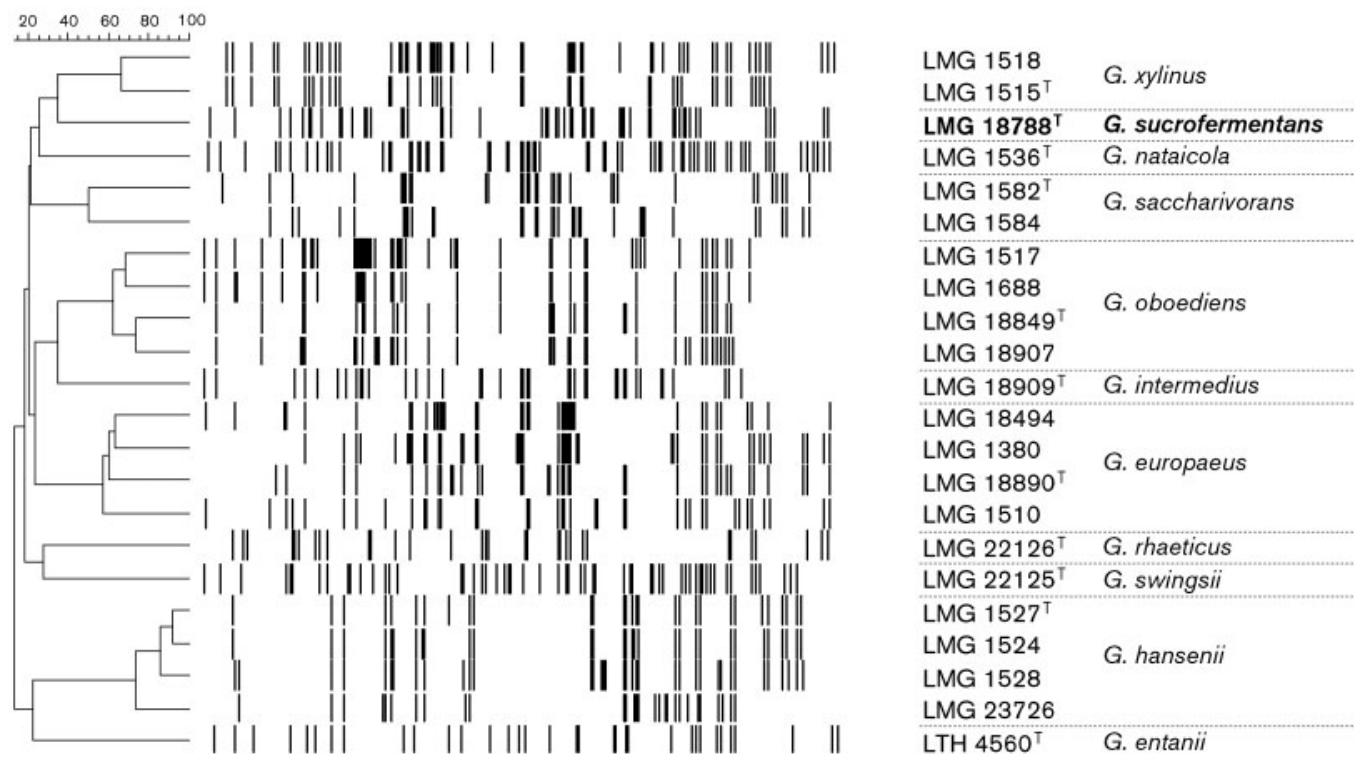

Fig. 2. (GTG) $)_{5}-P C R(a)$ and AFLP (b) DNA fingerprints of strain LMG $18788^{\top}$ and other strains of the G. xylinus species group. The dendrograms were constructed with the UPGMA method after calculation of the band pattern similarity (\%) using Pearson's correlation coefficient (a) and the Dice coefficient (b). 
Phenotypic and chemotaxonomic characterization of LMG 18788 has been performed previously (Toyosaki et al., 1995; Kojima et al., 1998). Results of this characterization are given in the species description. Phenotypic characteristics that differentiate LMG 18788 from phylogenetically related Gluconacetobacter species are presented in Table 2. Strain LMG 18788 could be differentiated from G. xylinus and $G$. nataicola, the phylogenetically nearest relatives, by the combination of its inability to produce 5-keto-Dgluconic acid from D-glucose and its ability to produce acid from sucrose and trehalose.

In conclusion, the results of the present study demonstrate that LMG 18788 should be classified in a distinct species in the genus Gluconacetobacter. The name Gluconacetobacter sucrofermentans sp. nov., comb. nov. is proposed. The results also indicate that the genus Gluconacetobacter should be split into two genera, if additional differentiating

Table 2. Characteristics that differentiate strain LMG $18788^{\top}$ from its phylogenetically nearest relatives

Strains: 1, G. sucrofermentans sp. nov., comb. nov. LMG $18788^{\mathrm{T}} ; 2, \mathrm{G}$. xylinus (4 strains); 3, G. nataicola LMG $1536^{\mathrm{T}}$; 4, G. swingsii LMG $25125^{\mathrm{T}}$; 5, G. europaeus (3 strains); 6, G. intermedius LMG $18909^{\mathrm{T}}$; 7, G. oboediens (4 strains); 8, G. rhaeticus LMG 22126 ${ }^{\mathrm{T}} ; 9$, G. saccharivorans (2 strains). + , Positive; - , negative; v, variable; $\mathrm{w}$, weakly positive; NR, not reported.

\begin{tabular}{|c|c|c|c|c|c|c|c|c|c|}
\hline Characteristic & 1 & 2 & 3 & 4 & 5 & 6 & 7 & 8 & 9 \\
\hline \multicolumn{10}{|l|}{$\begin{array}{l}\text { Production from } \\
\text { D-glucose of: }\end{array}$} \\
\hline 2-Keto-D-gluconic acid & + & + & + & + & $\mathrm{V}$ & - & + & + & + \\
\hline 5-Keto-D-gluconic acid & - & + & + & + & + & - & $\mathrm{V}$ & + & - \\
\hline \multicolumn{10}{|l|}{ Acid production from: $\dagger$} \\
\hline Glycerol & $\mathrm{W}$ & $\mathrm{V}$ & - & NR & + & NR & - & NR & + \\
\hline Sucrose & + & - & - & NR & - & NR & - & NR & - \\
\hline Trehalose & + & - & NR & NR & NR & NR & NR & NR & NR \\
\hline Cellulose production $\neq$ & + & + & + & + & - & + & $\mathrm{V}$ & + & - \\
\hline
\end{tabular}

${ }^{\star}$ Data in columns 4 and 8 were taken from Dellaglio et al. (2005); the other data were taken from Lisdiyanti et al. (2006). For G. xylinus, the result given is that of the type strain. Production of ketogluconic acids from D-glucose was determined for all strains using the TLC method described by Gosselé et al. (1980).

$\dagger$ Data in columns 1 and 2 were taken from Kojima et al. (1998); the other data were taken from Lisdiyanti et al. (2006). When reported, acid production from carbon sources was determined using the method described by Asai et al. (1964). Briefly, bacteria were incubated for 7 days at $28{ }^{\circ} \mathrm{C}$ in a medium consisting of $0.5 \%$ $(\mathrm{w} / \mathrm{v})$ yeast extract and $1 \%(\mathrm{w} / \mathrm{v})$ carbon source. The formation of acid was checked by adding $0.002 \%(\mathrm{w} / \mathrm{v})$ bromcresol purple to the cultured broths.

$\ddagger$ Data were taken from Lisdiyanti et al. (2006). Production of cellulose was verified for all strains by incubation in a growth medium containing D-glucose and by boiling formed pellicles in $5 \%(\mathrm{v} / \mathrm{v})$ $\mathrm{NaOH}$. Cellulose production was confirmed if the pellicles did not dissolve after $2 \mathrm{~h}$ of boiling. phenotypic characteristics can be identified. Finally, MLSA of the housekeeping genes $d n a K$, groEL and $r p o B$ was shown to be useful for species differentiation in the family Acetobacteraceae.

\section{Description of Gluconacetobacter sucrofermentans (Toyosaki et al. 1996) sp. nov., comb. nov.}

Gluconacetobacter sucrofermentans (su.cro.fer.men'tans. N.L. part. adj. sucrofermentans sucrose-fermenting).

Basonym: Acetobacter xylinus subsp. sucrofermentans corrig. Toyosaki et al. 1996.

This description is based on the description of Acetobacter xylinus subsp. sucrofermentans given by Toyosaki et al. (1995) and the results of Kojima et al. (1998). Cells are Gram-negative, non-motile, short rods, approximately $0.6-$ $0.8 \times 1.0-1.2 \mu \mathrm{m}$, occurring singly, in pairs or in chains. Colonies grown on GY agar for 3 days at $28{ }^{\circ} \mathrm{C}$ are beige, round, raised, rough, shiny and approximately $0.5 \mathrm{~mm}$ in diameter. Oxidase-negative, catalase-positive. Grows at 28 and $37{ }^{\circ} \mathrm{C}$ and at $\mathrm{pH}$ 3.0. Produces acetic acid from ethanol and dihydroxyacetone from glycerol. Oxidizes acetic acid and lactic acid to carbon dioxide and water and D-glucose to 2-keto-D-gluconic acid, but not to 5-keto-Dgluconic acid. The ubiquinone system consists mainly of ubiquinone-10. Grows on ethanol, D-xylose, D-galactose, D-glucose, glycerol, meso-erythritol, dulcitol, sucrose and trehalose as carbon sources. Produces acid from D-xylose, D-galactose, D-glucose, glycerol, meso-erythritol, sucrose and trehalose.

The type strain, LMG $18788^{\mathrm{T}}\left(=\mathrm{JCM} 9730^{\mathrm{T}}=\mathrm{DSM}\right.$ $\left.15973^{\mathrm{T}}\right)$, was isolated from a cherry. This strain is able to produce a large amount of cellulose from sucrose in agitated cultures. The DNA G + C content of LMG $18788^{\mathrm{T}}$ is $62.7 \mathrm{~mol} \%$.

\section{Acknowledgements}

This research was funded by the Federal Research Policy (Action for the promotion of and co-operation with the Belgian Coordinated Collections of Microorganisms, BCCM) and the Research Council of the Vrije Universiteit Brussel. The authors are very grateful to Ángel González and Katrien Vandemeulebroecke for their participation in the experimental work. The authors also wish to acknowledge Leentje Christiaens, Marjan De Wachter and Cindy Snauwaert for their technical support.

\section{References}

Asai, T., lizuka, H. \& Komagata, K. (1964). The flagellation and taxonomy of genera Gluconobacter and Acetobacter with reference to the existence of intermediate strains. J Gen Appl Microbiol 10, 95-126.

Brady, C., Cleenwerck, I., Venter, S., Vancanneyt, M., Swings, J. \& Coutinho, T. (2008). Phylogeny and identification of Pantoea species associated with plants, humans and the natural environment based on multilocus sequence analysis (MLSA). Syst Appl Microbiol 31, 447460 . 
Cleenwerck, I. \& De Vos, P. (2008). Polyphasic taxonomy of acetic acid bacteria: an overview of the currently applied methodology. Int $J$ Food Microbiol 125, 2-14.

Cleenwerck, I., De Wachter, M., González, Á., De Vuyst, L. \& De Vos, P. (2009). Differentiation of species of the family Acetobacteraceae by AFLP DNA fingerprinting: Gluconacetobacter kombuchae is a later heterotypic synonym of Gluconacetobacter hansenii. Int J Syst Evol Microbiol 59, 1771-1786.

De Bruyne, K., Schillinger, U., Caroline, L., Boehringer, B., Cleenwerck, I., Vancanneyt, M., De Vuyst, L., Franz, C. M. A. P. \& Vandamme, P. (2007). Leuconostoc holzapfelii sp. nov., isolated from Ethiopian coffee fermentation and assessment of sequence analysis of housekeeping genes for delineation of Leuconostoc species. Int J Syst Evol Microbiol 57, 2952-2959.

Dellaglio, F., Cleenwerck, I., Felis, G. E., Engelbeen, K., Janssens, D. \& Marzotto, M. (2005). Description of Gluconacetobacter swingsii sp. nov. and Gluconacetobacter rhaeticus sp. nov., isolated from Italian apple fruit. Int J Syst Evol Microbiol 55, 2365-2370.

De Vuyst, L., Camu, N., De Winter, T., Vandemeulebroecke, K., Van de Perre, V., Vancanneyt, M., De Vos, P. \& Cleenwerck, I. (2008). Validation of the $(\mathrm{GTG})_{5}$-rep-PCR fingerprinting technique for rapid classification and identification of acetic acid bacteria, with a focus on isolates from Ghanaian fermented cocoa beans. Int J Food Microbiol 125, 79-90.

Felsenstein, J. (1985). Confidence limits on phylogenies: an approach using the bootstrap. Evolution 39, 783-791.

Gillis, M. \& De Ley, J. (1980). Intra- and intergeneric similarities of the ribosomal ribonucleic acid cistrons of Acetobacter and Gluconobacter. Int J Syst Bacteriol 30, 7-27.

Gosselé, F., Swings, J. \& De Ley, J. (1980). A rapid, simple and simultaneous detection of 2-keto, 5-keto- and 2,5-diketogluconic acids by thin-layer chromatography in culture media of acetic acid bacteria. Zentbl Bakteriol Parasitenkd Infektionskr Hyg Abt 1 Orig Reihe C1, 178-181.

Kojima, Y., Tonouchi, N., Tsuchida, T., Yoshinaga, F. \& Yamada, Y. (1998). The characterization of acetic acid bacteria efficiently producing bacterial cellulose from sucrose: the proposal of Acetobacter xylinum subsp. nonacetoxidans subsp. nov. Biosci Biotechnol Biochem 62, 185-187.

Konstantinidis, K. T., Ramette, A. \& Tiedje, J. M. (2006). Towards a more robust assessment of intra-species diversity using fewer genetic markers. Appl Environ Microbiol 72, 7286-7293.
Lisdiyanti, P., Navarro, R. R., Uchimura, T. \& Komagata, K. (2006). Reclassification of Gluconacetobacter hansenii strains and proposals of Gluconacetobacter saccharivorans sp. nov. and Gluconacetobacter nataicola sp. nov. Int J Syst Evol Microbiol 56, 2101-2111.

Martens, M., Delaere, M., Coopman, R., De Vos, P., Gillis, M. \& Willems, A. (2007). Multilocus sequence analysis of Ensifer and related taxa. Int J Syst Evol Microbiol 57, 489-503.

Mesbah, M., Premachandran, U. \& Whitman, W. B. (1989). Precise measurement of the $\mathrm{G}+\mathrm{C}$ content of deoxyribonucleic acid by high-performance liquid chromatography. Int J Syst Bacteriol 39, 159167.

Naser, S. M., Thompson, F. L., Hoste, B., Gevers, D., Dawyndt, P., Vancanneyt, M. \& Swings, J. (2005). Application of multilocus sequence analysis (MLSA) for rapid identification of Enterococcus species based on rpoA and pheS genes. Microbiology 151, 2141-2150.

Saitou, N. \& Nei, M. (1987). The neighbor-joining method: a new method for reconstructing phylogenetic trees. Mol Biol Evol 4, 406425 .

Tindall, B. J., Rosselló-Móra, R., Busse, H.-J., Ludwig, W. \& Kämpfer, P. (2010). Notes on the characterization of prokaryote strains for taxonomic purposes. Int J Syst Evol Microbiol 60, 249-266.

Toyosaki, H., Kojima, Y., Tsuchida, T., Hoshino, K., Yamada, Y. \& Yoshinaga, F. (1995). The characterization of an acetic acid bacterium useful for producing bacterial cellulose in agitation cultures: the proposal of Acetobacter xylinum subsp. sucrofermentans subsp. nov. J Gen Appl Microbiol 41, 307-314.

Toyosaki, H., Kojima, Y., Tsuchida, T., Hoshino, K., Yamada, Y. \& Yoshinaga, F. (1996). Acetobacter xylinum subsp. sucrofermentans subsp. nov. In Validation of the Publication of New Names and New Combinations Previously Effectively Published Outside the IJSB, List no. 58. Int J Syst Bacteriol 46, 836-837.

Yamada, Y. \& Yukphan, P. (2008). Genera and species in acetic acid bacteria. Int J Food Microbiol 125, 15-24.

Yamada, Y., Hoshino, K. \& Ishikawa, T. (1997). The phylogeny of acetic acid bacteria based on the partial sequences of $16 \mathrm{~S}$ ribosomal RNA: the elevation of the subgenus Gluconoacetobacter to the generic level. Biosci Biotechnol Biochem 61, 1244-1251.

Yamada, Y., Hoshino, K. \& Ishikawa, T. (1998). Gluconacetobacter nom. corrig. [Gluconoacetobacter (sic)]. In Validation of Publication of New Names and New Combinations Previously Effectively Published Outside the IJSB. List no. 64. Int J Syst Bacteriol 48, 327-328. 